\title{
DPeertechz
}

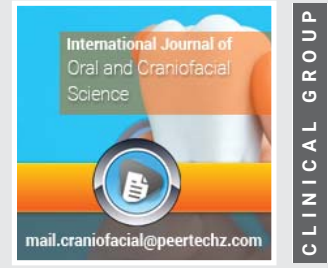

Research Article

\section{Radiographic evaluation of} secondary alveolar graff in the closure of alveolar fissures \section{of patients with cleft lip and}

\section{palate}

\author{
Acosta Rangel Monica $\mathrm{C}^{1 *}$ and Ozuna Ugalde Roberto ${ }^{2}$ \\ ${ }^{1}$ Administration of Hospitals and Public Health, Pediatric Maxillofacial Surgeon and Oral and \\ Maxillofacial Surgeon attached to the General Hospital National Medical Center La Raza of the IMSS \\ Pediatric Maxillofacial Surgery Service, Head of Lip Clinic and Palate DIF municipal Cuautitlán Izcalli, \\ Mexico \\ ${ }^{2}$ Oral and Maxillofacial Surgeon in municipal DIF Cuautitlán Izcalli Lip Clinic and cleft palate, private \\ practice, Mexico
}

Received: 13 February, 2020

Accepted: 15 July, 2020

Published: 16 July, 2020

*Corresponding author: Dra. Acosta Rangel Monica C, Administration of Hospitals and Public Health, Pediatric Maxillofacial Surgeon and Oral and Maxillofacial Surgeon attached to the General Hospital National Medical Center La Raza of the IMSS Pediatric Maxillofacial Surgery Service, Head of Lip Clinic and Palate DIF municipal Cuautitlán Izcalli, Mexico,

E-mail: acora_m@hotmail.com

Keywords: Integration; Secondary alveolar graft; Alveolar fissures; Cleft lip and palate; Planimetry https://www.peertechz.com

\section{Check for updates}

\section{Summary}

The X-ray evaluation of alveolar bone graft in lip-toveal palatines is one of the relevant topics in the management of this type of pathology since there are several studies conducted with parameters that are taken to determine the timing of the graft and its feasibility, as well as find the most accurate form and measure the integration of grafting dares of radiographic studies.

Objective: to measure the radiographic integration of secondary alveolar graft in the closure of alveolar fissures of patients with cleft lip and palate.

Material and method: observational, analytical, retrospective, longitudinal, descriptive, open, and series of cases from May 2013 to August 2019.

Results: The radiographic size of the preoperative and postoperative bone defect was measured, both on the Chelsea scale and the planimetry proposed in this study. In alveolar planimetry, Wilcoxon's test for horizontal dimension showed no significant difference, the vertical dimension in initial X-ray versus subsequent showed significant difference to treatment. For the Chelsea scale, a square Xi analysis was performed comparing initial vs. later X-rays, showing that there is significant difference.

Conclusions: The results demonstrate greater integration than reported in international literature. Orthopedic treatment, reaching GOSLON 1, helps us from a more stable and close anatomical state to reconstruction. The planimetry proposed in this study adds detail to other scales, as it showed more sensitivity than the Chelsea scale.

\section{Introduction}

In the rehabilitation of patients with Cleft Lip and Palate $(\mathrm{LPH})$ the treatment of alveolar fissure is essential, and secondary alveolar bone grafting with freeze-dried allogeneic bone represents an option with great therapeutic potential. Since no donor site is required generating greater morbidity in the patient and research has been proven that allogeneic bone can also be mixed with autogenous bone to improve graft volume in large clefts, which can save the patient an intervention of the bilateral iliac crest It is called the lip and palate cleft to the craniofacial malformation is congenital whose commitment is particularly focused on the upper lip , premaxil, hard and soft palate, therefore floor of nostrils. (Orthopedic and surgical 
treatment of the cleft lip and palate in children under two years of age. Evidence and Recommendations Guide: Mexico Clinical Practice Guide).

The most popular treatment protocols have been European ones, having on the one hand the Milan protocol of 1975 that indicated perform pre-surgical orthopedics, closure of the lip and nasal fissure; and subsequent reconstruction of the soft palate approximately 4 to 6 months of age, then closing the crack of the hard palate between 18 and 24 months of age and finally closing the alveolar fissure with a secondary bone graft before the canine rash between 10 and 12 years of age. From 1988 the Milan protocol was modified to simultaneously close the palatine fissure and the alveolar fissure (FA) the latter by means of a gingivoalveolplasty and avoid bone graft surgery at 10 years [1].

On the other hand, Oslo's surgical protocol includes the closure of the lip fissure (FLP) at 3 months of age at the same time as repairing the hard palate to a layer only of volleyball flap without any presurgical orthopedics; subsequently close the palatine fissure at 18 months of age. Alveolar cleft is repaired with a bone graft between 8 and 11 years [2].

From 1988 ones the Milan protocol was modified to simultaneously carry out the closure of the palatine fissure and the alveolar fissure (FA) the latter by means of a gingivoalveoplasty and to avoid bone graft surgery at 10 years [1].

On the other hand, Oslo's surgical protocol includes the closure of the lip crack (FLP) at 3 months of age at the same time as repairing the hard palate to a only layer of vomer flap without any pre-surgical orthopaedics; subsequently close the palatine fissure at 18 months of age. The alveolar slit is repaired with a bone graft between 8 and 11 years [2].

However, in 1998, it was reported that more than 200 different treatment protocols existed in Eurocleft alone, giving an idea of how difficult it is to unify treatment methods and criteria [3]. Due to the existence of many different treatment philosophies, the timing of treatment is considerably variable between cleft palate and lip centers. Special considerations may alter the sequence or time of the various procedures based on the functional or aesthetic needs of the individual [4].

The management of the alveolar fissure can be classified as primary, early secondary, secondary and late alveolar graft. The primary is done before the age of 2 and is usually done with the primary closure of the lip crack. Early secondary alveolar graft is performed between 2 and 5 years. Secondary alveolar graft is performed between the ages of 5 and 13 and is usually based on dental rash. And the late graft after the age of 13 [5].

The primary alveolar graft was described in the 1950 s by Nordin and Johansen who presented an autologous bone graft concomitant with the repair of soft lip and palate tissues. This concept gained popularity because at the same time they addressed both soft tissues and bone deficit and creates the possibility of harmonious facial growth and development. (12) Advantages include early stabilization of alveolar segments and improved arc shape, although alterations in the growth of the facial middle third have led to the abandonment of primary graft in several treatment centers [5].

The secondary alveolar bone graft is the most attractive and popular method for treating alveolar fissures. It is suggested when half of the canine root is almost complete. At this point in root development, the tooth shows an accelerated and active rash. On the other hand, it is considered that $75 \%$ to $90 \%$ of the dimensions of adult jaws are reached at 5 years. Therefore, it is possible that maxillary growth will not be significantly altered if the graft was performed at that time $[5,6]$.

The timing of these grafts should be evaluated individually to aid the natural rash of the tooth in the cracked region. Corrective surgeries are performed using autologous, allogeneic and synthetic materials for the reconstruction of the alveolar fissure [7].

Evaluation should begin with the history of all previous surgeries and complete physical examination, which includes: teethadjacent to the fissure, fissure size, fistulas present, dental arch shape, degree of bow collapse, cross bite, and position of the premaxilla in case of a bilateral cleft. The image is essential and typically a panoramic $\mathrm{x}$-ray is satisfactory. A medical-grade CT scan is not recommended [5].

Mars, et al. (1987) published a method called GOSLON (Great Ormond Street, London and Oslo) criterion to rate the outcome of treatment in patients with HPL. Patients are classified into five groups [8]. Based on the maxillary and molar ratio, in which the objective is to improve the conditions of the bone processes by squealing them and within these five optimal groups are those in group 1.2 and 3 [9].

Once the maxillary conditions are suitable, the objective should be the placement of the graft using some surgical technique for the closure of the FLP there is a standardized method that was first described by Boyne and Sands. A vestibular gingival marginal incision is raised a wide mucoperhasic flap including at least one lateral tooth and mesial to the cleft. In the area of the cleft itself, an incision is made from the vestibular groove. If the slit extends to the nasal cavity, the nasal mucosa is elevated, allowing a stress-free repair of that layer. After the nasal layer and palatine flaps have been repaired, the bone graft is placed. Finally, the grafted site is covered by reattaching the vestibular mucoperiestic flaps [10].

Clinical, radiographic and biological evaluations have estimated the success rate of bone allograft in the range between $60 \%$ and $90 \%$ [18]. A comparative study of closure of alveolar fissures of patients with cleft lip and palate treated with allogeneic bone graft lyophilized against hip autograft, it was found that patients treated with allogeneic graft had a $26 \%-75 \%$ integration while $86.7 \%$ of patients treated with autograft had an integration of $51-100 \%$ [11].

In a retrospective study of Benlidayi and cabbage. compared the long-term results of secondary alveolar bone graft using bovine-derived hydroxyapatite versus autogenous bone, the difference between the two was not significant achieving radiographic success in the $100 \%$ xenograft group [12]. 
When a postoperative complication develops the surgical result may be compromised. The need for repair increases the overall costs of treatment, exposes the patient once again to risks related to operation and general anesthesia. The most common complications are graft exposure associated with wound dehiscence, wound infection and graft reabsorption as reported by Meireles [13]. The important factors affecting the outcome of secondary alveolar bone grafts are that the graft is placed before the rash of the canines and the type of HPL. According to Jia, et al. they obtained success rates according to hpp types divided into unilateral lip fissure and alveolar process with $94 \%$, unilateral cleft Lip and Palate (LPHU) with 95\% and bilateral cleft lip and palate (LPHB) with 91\% and no statistical difference if graft it is placed before the rash of the canine, in case after the rash of the canine the statistical difference presents between unilateral lip fissure and alveolar process and LPHB [10].

For consistent and adequate visualization of the alveolar graft, Computed Axial Tomography or Conical Beam Computed Tomography can be used in cuts with $1 \mathrm{~mm}$ increments comparing the preoperative volume of the defect at the same limits, with the volume of postoperative residual defect.

However, the image of an X-ray is satisfactory and a medical-grade CT scan may not be recommended $[1,10,14]$.

The radiographic image in the presence of erupted canine is evaluated by the criteria of Bergland, et al. (Bergland, Semb, \& Abyholm, 1986) [14].

Using the Bergland scale it is not possible to evaluate slits when the canine is not erupted, in these cases the Chelsea alveolar bone graft scale is suggested (Witherow, Cox, Jones, Carr, \& Waterhouse, 2002 [15].

\section{Material and method}

Observational, analytical, retrospective, longitudinal, descriptive, open, and series of cases of patients with unilateral cleft lip and palate, attended by the multidisciplinary team of the General Hospital National Medical Center La Raza. Nonrandom sample for convenience. Patients diagnosed with unilateral cleft lip and palate who were treated with only one allogeneic secondary alveolar graft performed at La Raza National Medical Center in the period May 2013 to August 2019 between 4 and 13 years whose GOSLON classification out of group 1.2 and 3 that had preoperative and postoperative panoramic $\mathrm{x}$-ray. after the graft placement, an analysis was performed by decaling the radiopaca structures defining the size of the alveolar fissure by measuring the largest dimension of the alveolar in the horizontal and vertical planes. By analyzing the type of distribution of the variables, applying parametric and/or nonparametric tests.

All patients diagnosed with unilateral cleft lip and palate not associated with syndrome treated with only a secondary alveolar graft performed at La Raza National Medical Center in may 2015 to August 2019 between 4 and 13 years whose classification of GOSLON was group 1 and 2, which have preoperative and postoperative panoramic $\mathrm{x}$-ray, were taken into account. Patients with exclusion criteria were found under 3 years of age and over 14, incomplete studies, who had dehiscence and/or graft rejection, classification GOSLON group 3 and 4 .

The standardized method was described by Boyne and Sands (Figure 1). A vestibular gingival marginal incision, to raise a wide mucoperiestic flap including at least one lateral tooth and mesial to the cleft. In the area of the cleft an incision is made from the vestibular groove. If the slit extends to the nasal cavity, the nasal mucosa is elevated, allowing a stressfree repair of that layer. After the nasal layer and palatine flaps have been repaired, the allogeneic bone graft was placed (Figure 2). Finally, the grafted site is covered by reattaching the vestibular mucoperiestic flaps (Figures 3,4).

Pre- and postoperative panoramic X-rays were obtained at graft placement, an analysis was performed by the trace of the radiopaque structures defining the size of the alveolar fissure measuring the largest dimension of the alveolar in the horizontal and vertical planes as well as its classification on the Chelsea scale. Nonparametric tests were performed.

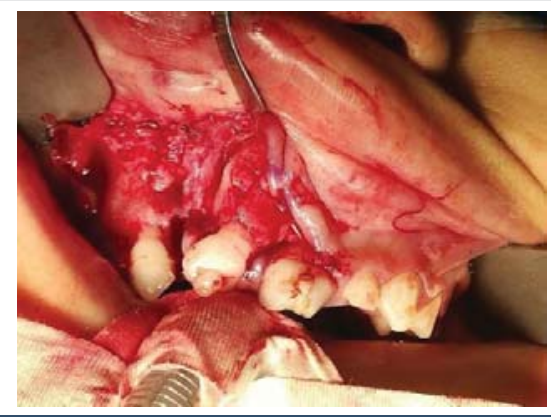

Figure 1: Tecnica de boyne $Y$ sands.

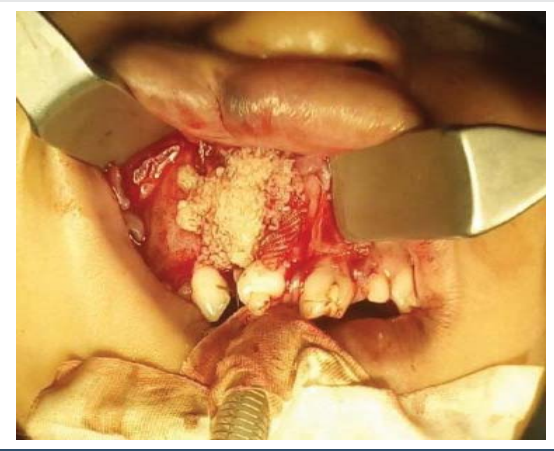

Figure 2: Alogenico graft location.

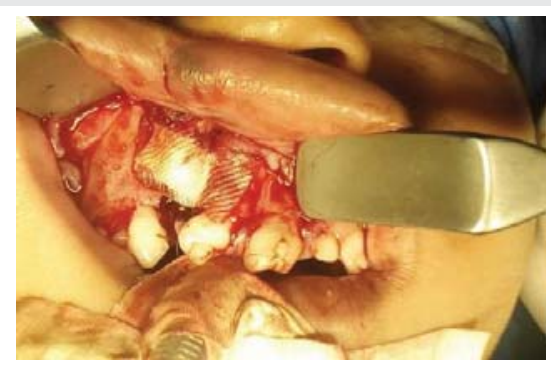

Figure 3: Membrane placement. 


\section{Results}

Of the 43 cases found in the Pediatric Maxillofacial Surgery service records of La Raza National Medical Center in the period May 2013 to August 2018 only 19 met the inclusion criteria, 10 cases were diagnosed with LPHUD (52.63\%) and 9 of LPHUI $(47.36 \%)$, in turn, 8 were female ( 5 LPHUID $26.31 \%$ and 3 LPHUI $15.78 \%$ ) 11 men (6 LPHUI $31.57 \%$ and 5 LPHUD $26.31 \%$ ) . The age at the time of graft placement surgery oscillo between 4.11 and 12.97 years, having an average of 7.91 years. And they all had a GOSLON 1 rating.

The records for each case, starts on the pre-surgical and post-surgical panoramic $\mathrm{x}$-ray between 0 and 4 months after the surgical act, finally at 6 months plotting on the alveolar planimetry suggested in the study, as well as the classification of Chelsea. (Figure 5).

In the alveolar planimetry of the initial $\mathrm{x}$-ray, the maximum fissure values of $15 \mathrm{~mm}$ horizontal and $20 \mathrm{~mm}$ vertical were obtained with an average of $7.36 \mathrm{~mm}$ horizontal and $7.89 \mathrm{~mm}$ vertical. The maximum values on the $\mathrm{X}$-ray of $0-4$ months were $15 \mathrm{~mm}$ horizontal and $16 \mathrm{~mm}$ vertical. On the final $\mathrm{x}$-ray the maximum values were $18 \mathrm{~mm}$ horizontal and 12 vertical with an average $5.73 \mathrm{~mm}$ horizontal and $3.73 \mathrm{~mm}$ vertical. In the pre, post-surgical and final radiographic series the minimum value was 0 in both dimensions. (Tables 1,2 Y2).

On the Chelsea scale for the initial X-ray, 5 cases A (26.32\%), 3 cases B $(15.79 \%), 2$ cases C (10.53\%), o cases D and E, 9 cases $\mathrm{F}(47.36 \%)$ were obtained in post-surgical x-rays $0-4$ months there were 14 cases A $(73.68 \%), 1$ case B $(5.26 \%), 2$ cases C

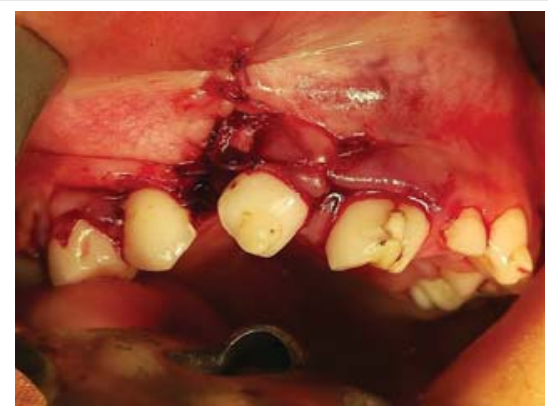

Figure 4: Close of the vestibular mucoperiostic close.

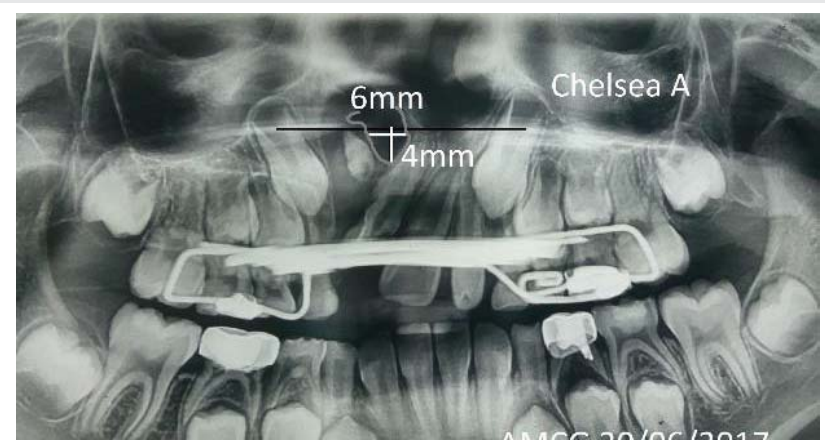

Figure 5: Panoramic x-ray. A trace of alveolar planimetry and Chelsea scale assignment, the extension ocf the contralateral nasal floor was previously drawn as the upper limit.
Table 1: Alveolar Planimetria Values in Horizontal and Vertical Sense of The Alveolar Securities and Postoperative Values 0 To 4 Months.

\begin{tabular}{|c|c|c|c|c|c|}
\hline & Horizontal & Vertical & & Horizontal & Vertical \\
\hline MAX & 15 & 20 & MAX & 15 & 16 \\
\hline MIN & 0 & 0 & MIN & 0 & 0 \\
\hline PROMEDIO & 7.368421053 & 7.89473684 & PROMEDIO & 5.68421053 & 4.05263158 \\
\hline MODA & 0 & 0 & MODA & 0 & 0 \\
\hline MEDIANA & 8 & 7 & MEDIANA & 6 & 3 \\
\hline
\end{tabular}

\begin{tabular}{|l|l|l|l|l|l|}
\hline DESVIACION & 5.23036568 & 6.85480154 & DESVIACION & 5.49800602 & 4.92695178
\end{tabular}

\begin{tabular}{|l|l|l|l|l|l|}
\hline CURTOSIS & -1.021055198 & -0.93396219 & CURTOSIS & -1.60049113 & 1.3733716
\end{tabular}

\begin{tabular}{|l|l|l|l|l|l|} 
ASIMETRIA & -0.262192533 & 0.46981111 & ASIMETRIA & 0.19280673 & 1.3601896
\end{tabular}

Table 2: Alveolar Planimetria Values In Horizontal And Vertical Sense Of The Alveolar Securities.

\begin{tabular}{|c|c|c|}
\hline & Horizontal & Vertical \\
\hline MAX & 18 & 12 \\
\hline MIN & 0 & 0 \\
\hline PROMEDIO & 5.73684211 & 3.73684211 \\
\hline MODA & 0 & 0 \\
\hline MEDIANA & 6 & 4 \\
\hline DESVIACION & 5.52612085 & 3.52518093 \\
\hline CURTOSIS & -0.47776535 & -0.25085662 \\
\hline ASIMETRIA & 0.55311936 & 0.51584189 \\
\hline
\end{tabular}

(10.53\%), 1 case D (5.26\%), o cases E, and one case F (5.26\%) (Illustration 9). In the final $\mathrm{x}$-ray at more than 4 months there were 14 cases A $(73.38 \%)$, 3 cases B $(15.76 \%)$, o cases C, 2 cases D (10.53\%) and o cases E and F Graphs 1-3.

For alveolar planimetry, Wilcoxon's statistic analysis was performed for paired samples with a $.0 .05 \mathrm{x}$-ray, comparing the initial $\mathrm{x}$-rays against post-surgical and then initial $\mathrm{x}$-ray against final $\mathrm{x}$-ray. In the case of initial $\mathrm{x}$-ray against postsurgical $\mathrm{x}$-ray we obtained a statistical t-value of 18 and a critical value of 17 for the horizontal dimension accepting the null hypothesis of no statistical difference as in the initial $\mathrm{X}$-rays against end in the same horizontal dimension with a statistical t of 28 and a critical value of 21 . On the other hand, the vertical dimension in initial $\mathrm{x}$-ray versus post-surgical had a statistical $t$ of 13 and a critical value of 25 rejecting the null hypothesis and accepting the altering that shows significant difference to the treatment, as well as the comparative between initial and final $\mathrm{x}$-rays relative to the vertical dimension with a statistical t of 28 and a critical value of 35 .

For the Chelsea scale, a square Xi analysis was performed comparing initial $\mathrm{x}$-rays against post-surgical $0-4$ months with a Received Xi of 12.6631 and subsequently initial versus final X-rays were compared with a squareD Xi obtained from 17.2631 in both cases, 5 degrees of freedom were used, a critical $\mathrm{Xi}$ of 11,070 and a critical square Xi of 11,070 , which rejects the null hypothesis, as there is significant difference between initial versus post-surgical image of $0-4$ months and against the final. And according to the final $\mathrm{x}$-ray, 14 cases $\mathrm{A}(73.38 \%)$ and $3 \mathrm{~B}$ cases $(15.76 \%$ ) are obtained, representing $89.14 \%$ of patients exceeding the $75 \%$ reported in the international literature. 


\section{CHELSEA INICIAL}
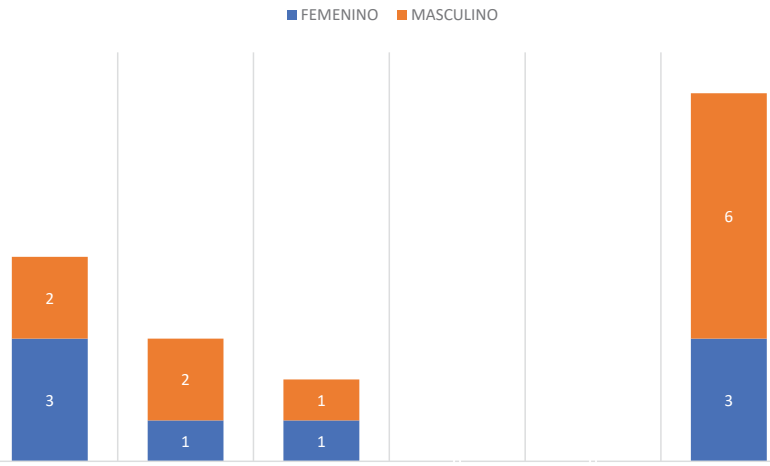

Graph 1: Initial chelsea scale frequency by genero.

CHELSEA POST QX 0 A 4 MESES

- FeMENino amasculino
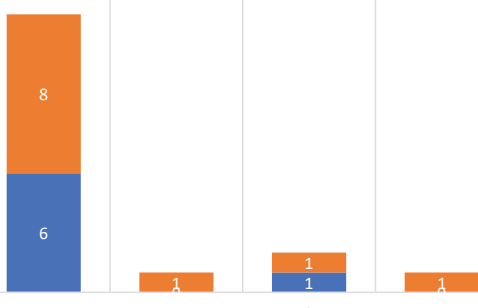

Graph 2: Chelsea postquirurgica scale frequency from 0 to 4 months per genero.

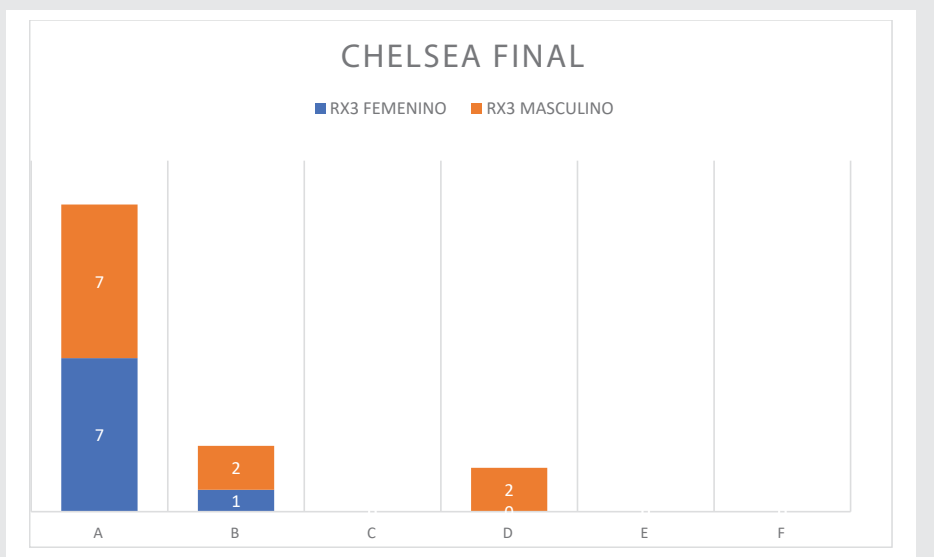

Graph 3: Final chelsea scale frequency (more than 4 months) by genero.

\section{Discussion}

This study is the first to propose a planimetry for alveolar fissures, although there is a three-dimensional imaging analysis using conical beam tomography, we use a panoramic $\mathrm{x}$-ray imaging system which represents lower cost and less radiation to the patient, without losing accuracy in their analysis. In turn, the radiographic evaluation presents a variety of classifications which in its attempt to encompass all the characteristics of the pathology overlook others just as important. In the particular case of the Chelsea classification it focuses on the presence of bone between the teeth on each side of the fissure, ignoring the reconstruction of the nasal floor [15], on the other hand the alveolar planimetry that we propose in this study remains limited to the upper portion of the crack without taking into account the remaining defect that remained in the lower portion of the bone bridge, so we consider that both analyses can be complementary. In turn, in the most severe cases the plane projected by the pyriform cleavage on the healthy side was used as the upper limit. It is therefore clear that in addition to the alveolar reconstruction another goal is also the restitution of the nasal floor.

Unlike most studies, in this work alveolar graft was performed in orthopedically treated patients of whom $100 \%$ were on the GOSLON 1 scale, favoring to start from a point closer to the anatomical reconstruction target. This is achieved largely by presurgical orthopedics [9], whose objective is palatine expansion to improve dental arch relationships before grafting as well as improve access during nasal floor closure. One disadvantage is that the device should be stopped placing for an additional 3 months after grafting during the consolidation period [3] which predisposes a relapse to the position of the jaws if treatment is not resumed in a timely manner, suggested the use of an acetate retainer.

The age at the time of graft placement surgery oscillo between 4.11 and 12.97 years, having an average of 7.91 years which is optimal considering that about $75 \%$ to $90 \%$ of the dimensions of adult jaws are reached at 5 years choosing that mome to avoid altering maxillary growth $[3,4]$.

Using the Bergland scale it is not possible to evaluate clefts when the canine is not erupted, in these cases the Chelsea alveolar bone graft scale is suggested [15].

According to the international literature $75 \%$ of patients treated with grafting had a tomographic integration of $26-75 \%$ [11], in this study a greater integration was obtained taking into account the final $x$-ray to more than 4 months with 14 cases with a scale Chelsea A (73.38\%) and 3 cases Chelsea B $(15.76 \%)$ which are considered to be optimal results, indicating an optimal integration of more than $89 \%$ of cases, favoring an adequate alveolar reconstruction, in turn also observes the significant reduction of the vertical dimension which leads to a proper reconstruction of the nasal floor. On the other hand, while the means of horizontal dimensions on X-rays are different, during statistical analysis they do not show significant changes which can be interpreted as less integration into the horizontal dimension and in turn, this planimetry, shows greater sensitivity than the Chelsea scale.

While the support for orthopaedic treatment is clear, one particular case was negatively affected by orthodontic treatment, which coincides with studies reporting a resorption between 14 and $100 \%$ with an average of $36.46 \%$ [16-26].

\section{Conclusions}

After observing the results obtained with the alveolar graft compared to the initial $\mathrm{x}$-ray we can conclude that the alveolar graft in patients with $\mathrm{HpL}$ contributes to the closure 
of alveolar fissures in the treatments performed by the alveolar Maxillofacial surgery of the National Medical Center La Raza, obtaining adequate and predictable results.

We conclude that the orthopedic prior treatment helps us from an anatomical state more stable and close to reconstruction and part of the success is to lead to an anatomically correct relationship according to the GOSLON scale.

The use of panoramic $x$-ray in the early evaluation of the secondary alveolar graft is a great tool for its low cost as well as its low radiation exposure to the patient. Just as it is versatile for measuring at different scales.

The planimetry proposed in this study is useful as it adds detail to other scales, in turn helping to improve treatment evaluation as it showed more sensitivity than the Chelsea scale. The planimetry of this study takes into account the reconstruction of the nasal floor, in addition that it is practical simple and inexpensive to be able to establish criteria for decision-making regarding the placement of the graft improving the aesthetic and functional conditions of the middle third region allowing the evolution of dental development to improve and stabilizing the lack of fusion of the maxillary segments from the placement of the graft considering key moments for facial growth of the patient.

The fact that it has not had significant changes in the horizontal dimension highlights both the need for presurgical orthopedics and a starting point for anatomical reconstruction, and the need for proper repair of the nasal floor.

We propose alveolar planimetry as a quantitative method in early evaluation of grafts, alveolar reconstruction and nasal floor in patients with HPL, as well as long-term follow-up with the multidisciplinary team.

Taking into account the Chelsea scale to evaluate the graft early favors the success of the treatment.

The average age with these results was 7.91 years, indicating the success of secondary graft as a part of the protocol.

\section{Notes}

\section{Conflicts of interest}

The authors have completed the ICMJE Conflict of Interest Statement form, and declare that they have not received funding for the report; not have financial relationships with organizations that might have interests in the published article in the last three years; and not have other relationships or activities that could influence the published article. The forms can be requested by contacting the responsible author or the editorial address of the Magazine. To the case as having been reviewed by the ethics committee of the institution which carried out such work.

\section{Financing}

The authors state that there were no external sources of funding.

\section{Thanks}

To Dr. America Ayuso Arce, for her tireless work in the management of LPH patients.

\section{References}

1. Brusati R (2016) Evolution of my philosophy in the treatment of unilateral cleft lip and palate. J Craniomaxillofac Surg 44: 901-911. Link: https://bit.ly/2OqGcWa

2. Meazzini M, Rossetti G, Garattini G, Semb G, Brusati R (2010) Early secondary gingivo-alveolo-plasty in the treatment of unilateral cleft lip and palate patients: 20 years experience. J Craniomaxillofac Surg 38: 185-191. Link: https://bit.ly/2ZvZZd6

3. Velázquez JM, Berlanga F, Estrada H, Álvarez J, Flores M (2012) Prevención de las malformaciones postquirúrgicas en pacientes con labio y paladar hendidos. Fundamentos y protocolo. Cir Plast 22: 57-66. Link: https://bit.ly/38ZxYxT

4. Miloro MG, Ghali E, Larsen PE, Waite PD (2004) Peterson's principles of oral and maxillofacial surgery. $2^{\text {nd }}$ ed. Hamilton: B.C. Decker, Inc.

5. Dao AM, Goudy SL (2016) Cleft Palate Repair, Gingivoperiosteoplasty, and Alveolar Bone Grafting. Facial PlastSurgClin N Am 24: 467-476. Link: https://bit.ly/32mfsyn

6. Seifeldin S (2016) Is alveolar cleft reconstruction still controversial? (Review of literature). Saudi Dent J 28: 3-11. Link: https://bit.ly/395IGUv

7. Sharif F, Rehman IU, Muhammad N, MacNeil S (2016) Dental materials for cleft palate repair. Mater Sci Eng C Mater Biol Appl 1: 1018-1028. Link: https://bit.ly/30iFP5F

8. Mars M, Plint D, Houston W, Bergland O, Semb G (1987) The Goslon Yardstick: a new system of assessing dental arch relationships in children with unilateral clefts of the lip and palate. Cleft Palate J 24: 314-322. Link: https://bit.ly/2DNHvfT

9. Jorge P, Gnoinski W, Laskos KV, Carrara CFC, Garib DG, et al. (2016) Comparison of two treatment protocols in children with unilateral complete cleft lip and palate: Tridimensional evaluation of the maxillary dental arch. $J$ Craniomaxillofac Surg 44: 1117-1122. Link: https://bit.ly/2DK2oZf

10. Jia Y, Fu M, Ma L (2006) Long-term outcome of secondary alveolar bone grafting in patients with various types of cleft. $\mathrm{Br} \mathrm{J}$ Oral Maxillofac Surg 44 308-312. Link: https://bit.ly/2WjAKZF

11. Shirani G, Abbasi AJ, Mohebbi SZ, Moharrami M (2017) Comparison between autogenous iliac bone and freeze-dried bone allograft for repair of alveolar clefts in the presence of plasma rich in growth factors: A randomized clinical trial. J Craniomaxillofac Surg 45: 1698-1703. Link: https://bit.ly/2WqH4yt

12. Benlidayi M, Tatli U, Kurkcu M, Uzel A, Oztunc H (2012) Comparison of bovinederived hydroxyapatite and autogenous bone for secondary alveolar bone grafting in patients with alveolar clefts. J Oral Maxillofac Surg 70: e95-e102. Link: https://bit.ly/2CjKFr8

13. Borba A, Borges A, Silva Cd, Brozoski M, Mda GNH, et al. (2014) Predictors of complication for alveolar cleft bone graft. $\mathrm{Br} \mathrm{J}$ Oral Maxillofac Surg 52: 174 178. Link: https://bit.ly/3fBbZ2B

14. Bergland O, Semb G, Abyholm F (1986) Elimination of the residual alveolar cleft by secondary bone grafting and subsequent orthodontic treatment. Cleft Palate J 23: 175-205. Link: https://bit.ly/3j1Jhdk

15. Witherow H, Cox S, Jones E, Carr R, Waterhouse N (2002) A new scale to assess radiographic success of secondary alveolar bone grafts. Cleft Palate Craniofac J 39: 255-260. Link: https://bit.ly/30u5Z5F

16. Norma Oficial Mexicana NOM-012-SSA3-2012. Secretaria de Salud. Disponible en. Link: https://bit.ly/2Wn4JQi

Citation: Monica CAR, Roberto OU (2020) Radiographic evaluation of secondary alveolar graff in the closure of alveolar fissures of patients with cleft lip and palate. Int J Oral Craniofac Sci 6(2): 021-027. DOI: https://dx.doi.org/10.17352/2455-4634.000046 
17. Tratamiento ortopédico y quirúrgico del labio y paladar hendido en niños menores de dos años de edad. Guía de evidencias y recomendaciones: guía de práctica clínica México. Cenete; 2017

18. Gorlin R, Cervenka J, Pruzansky S (1971) Facial clefting and its syndromes. Birth Defects Orig Artic Ser 7: 3-49. Link: https://bit.ly/2DOcUPh

19. Shi M, Wehby GL, Murray JC (2008) Review on genetic variants and maternal smoking in the etiology of oral clefts and other birth defects. Birth Defects Res C Embryo Today 84: 16-29. Link: https://bit.ly/3j5El7f

20. Dávalos-Rodríguez IP, Ramírez-Lizardo EJ, Mena JP (2009) Variante C677T del gen metilenotetrahidrofolatoreductasa en niños mexicanos con labio/paladar hendido. Rev Med Inst Mex Seguro Soc 47: 549-552. Link: https://bit.ly/3j6V5uU

21. Rangel MA, Montes DP, Mesa BF (2013) Frecuencia y factores de riesgo en labio y paladar hendidos. Revista Mexicana de CirugíaBucal y maxilofacial 9 109-112. Link: https://bit.ly/2B2IJ6Y

22. Watkins S, Meyer R, Strauss R, Aylsworth A (2014) Classification, Epidemiology, and Genetics of Orofacial Clefts. Clin Plastic Surg 41: 149-163. Link: https://bit.ly/32odjlC
23. Han K, Jeong W, Yeo H, Choi J, Kim J, et al. (2017) Long-term results of secondary alveolar bone grafting using a technique to harvest pure calvarial cancellous bone: Evaluation based on plain radiography and computed tomography. J Plast Reconstr Aesthet Surg 70: 352-359. Link: https://bit.ly/2DHOdnr

24. Eppley BL, Pietrzak WS, Blanton MW (2005) Allograft and Alloplastic Bone Substitutes: A Review of Science and Technology For the Craniomaxillofacial Surgeon. J Craniofac Surg 16: 981-989. Link: https://bit.ly/3j4ca8Z

25. Reglamento de la Ley General de Salud en Materia de Investigación para la Salud. Disponible en.

26. World Medical Associations Declaration of Helsinki Ethical principles for medical research involving human subjects. Adopted by the 18th WMA General Assembly, Helsinki, Finland, June 1964; amended by the 29th WMA General Assembly, Tokyo, Japan, October. In 1975; 35th WMA General Assembly, Venice, Italy, October 1983; 41st. WMA General Assembly, Hong Kong, September 1989; 48th WMA General Assembly, Somerset West Republic of South Africa, October 1996, and the 52nd WMA General Assembly, Edinburg, Scotland; October 2000; Note of clarification on paragraph 29 added by the WMA General Assembly, Washington 2002. Disponible en. Link: https://bit.ly/2DOevEL

\section{Discover a bigger Impact and Visibility of your article publication with}

\section{Peertechz Publications}

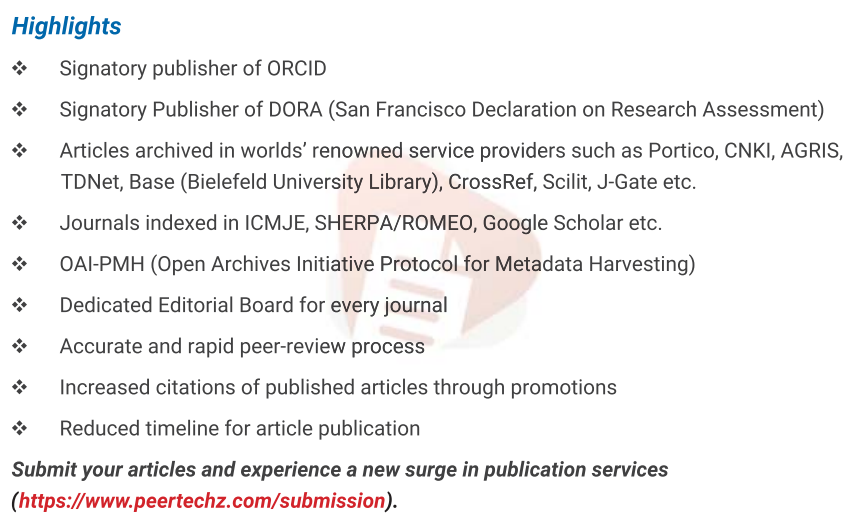

Peertechz journals wishes everlasting success in your every endeavours.

Copyright: @ 2020 Monica CAR, et al. This is an open-access article distributed under the terms of the Creative Commons Attribution License, which permits unrestricted use, distribution, and reproduction in any medium, provided the original author and source are credited. 